\title{
Recruiters to randomised trials can be trained to facilitate recruitment and informed consent by exploring patients' treatment preferences
}

\author{
Nicola Mills ${ }^{1 *}$, Jane Blazeby ${ }^{1}$, Freddie Hamdy ${ }^{2}$, David Neal ${ }^{3}$, Bruce Campbell ${ }^{4}$, Jenny Donovan ${ }^{1}$ \\ From 2nd Clinical Trials Methodology Conference: Methodology Matters \\ Edinburgh, UK. 18-19 November 2013
}

\section{Background}

Patient preferences for treatments are often cited as barriers to recruitment in randomised controlled trials (RCTs) but little is known about how to approach this issue in the context of trial recruitment. We investigated how recruitment staff reacted to patients' treatment preferences within three different pragmatic RCTs.

\section{Methods}

Audio-recordings of 85 RCT recruitment appointments with 69 participants in three UK multicentre RCTs were analysed using content and thematic analysis. Recruiters' responses to treatment preferences were assessed in one $\mathrm{RCT}$ (ProtecT), where training on exploring preferences was given, and compared with two other RCTs where this type of specific training was not given.

\section{Results}

Recruiters elicited treatment preferences similarly in all RCTs, but responses to them differed substantially. In the Protec T RCT, recruiters explored participants' preferences at length in four key ways: eliciting and acknowledging the preference rationale, balancing treatment views, empathising with the situation, and emphasising the need to keep an open mind and consider all treatments. Conversely in the other RCTs, treatment preferences were usually accepted by recruiters with little discussion and few patients randomised.

\section{Conclusion}

Recruiters can be trained to elicit and address patients' treatment preferences enabling those who may not have

University of Bristol, Bristol, UK

Full list of author information is available at the end of the article considered trial participation to do so. Training interventions for recruiters are required to facilitate recruitment and informed consent.

\section{Acknowledgements}

We acknowledge the study funders (MRC ConDuCT Trials Methodology Hub, NIHR HTA and RfPB), all participating clinicians and patients, and the Cls and Pls of the trials.

\section{Authors' details}

'University of Bristol, Bristol, UK. ${ }^{2}$ University of Oxford, Oxford, UK. ${ }^{3}$ University of Cambridge, Cambridge, UK. ${ }^{4}$ University of Exeter, Exeter, UK.

Published: 29 November 2013

doi:10.1186/1745-6215-14-S1-063

Cite this article as: Mills et al:: Recruiters to randomised trials can be trained to facilitate recruitment and informed consent by exploring patients' treatment preferences. Trials 2013 14(Suppl 1):063.

Submit your next manuscript to BioMed Central and take full advantage of:

- Convenient online submission

- Thorough peer review

- No space constraints or color figure charges

- Immediate publication on acceptance

- Inclusion in PubMed, CAS, Scopus and Google Scholar

- Research which is freely available for redistribution

\section{() Biomed Central}

( 2013 Mills et al; licensee BioMed Central Ltd. This is an Open Access article distributed under the terms of the Creative Commons Attribution License (http://creativecommons.org/licenses/by/2.0), which permits unrestricted use, distribution, and reproduction in any medium, provided the original work is properly cited. 